\title{
A double blind randomized study to compare efficacy of $5 \%$ Dapsone gel vs combination of Adapalene-clindamycin gel in the treatment of mild to moderate Acne vulgaris
}

\begin{abstract}
Background: Acne vulgaris is a disorder of the pilosebaceous glands affecting mainly the adolescent population and it is associated with significant morbidity.

Aim: To compare the efficacy of 5\% Dapsone gel against a combination of $1 \%$ clindamycin- $0.1 \%$ adapalene gel in the treatment of mild to moderate acne vulgaris.

Materials and methods: Clinically diagnosed cases of Acne vulgaris were evaluated using Global Acne Grading system (GAGS) and those classified as mild to moderate were included in the study. Dapsone $5 \%$ gel and combination of $1 \%$ clindamycin$0.1 \%$ adapalene gel were repacked in similar looking containers. Patients received the medication randomly such that 30 of them applied $5 \%$ dapsone gel and other 30 applied a combination of clindamycin-adapalene (AC) gel. They were reviewed at 4th week and their GAGS score were recorded.
\end{abstract}

Results: This study comprised of 60 subjects of which, $48(80 \%)$ were men and $12(20 \%)$ women. 24 subjects followed up after 4 weeks. Out of $24(40 \%), 14(58 \%)$ had improved as reflected by Wilcoxon signed rank test. Of these 14,7 belonged to Dapsone and 7 others to clindamycin adapalene. The other 36(60\%) subjects who couldn't follow-up in person were questioned telephonically. $6(35 \%)$ out of $17(47 \%)$ from the adapalene clindamycin (AC) group and 5(26\%) out of $19(53 \%)$ from the dapsone group said their acne had improved. 2 out of 17 from AC group and 8out of 19 from Dapsone group said they did not find any improvement with the medication and had thus not returned for follow up. 2 out of 17 from AC group and 1 out of 19 from dapsone group had skin irritation and or erythema due to which they dropped out of the study. 7 out of 17 from AC group and 5 out of 19 from Dapsone group, said they had not used the drugs regularly because of exams, travel and other reasons.

Conclusion: Adapalene-clindamycin group showed good efficacy and lesser side effects compared to the dapsone group. This study also highlights the fact that acne cases are poorly compliant with therapy. Larger studies are required to analyze the reasons for poor compliance in acne as well as efficacy and tolerability of various newer anti acne preparations.

Keywords: acne vulgaris, dapsone, clindamycin, adapalene, GAGS
Volume 2 Issue 4 - 2018

\author{
Kamoji SG, Huggi G, Pise GA, Nayak JJ, \\ Dastikop SV, Patil MN \\ Department of Dermatology, Belagavi Institute of Medical \\ Sciences, India
}

Correspondence: Kamoji Sushruth Guruputra, Department of Dermatology, Belagavi Institute of Medical Sciences, Belagavi, Karnataka-590005, India, Email drsushruthk@yahoo.co.in

Received: February 15, 2018 | Published: August 10, 2018

\section{Introduction}

Acne vulgaris is a common condition encountered in dermatology OPD. It affects approximately $85 \%$ of individuals in the age group of 11 and 24years. ${ }^{1}$ The pathogenesis of acne is comprises of 4 main steps which are as follows:
i. Aberrant follicular keratinization,
ii. Inflammation
iii. Excess sebum and

iv. Propionibacterium acnes. ${ }^{2}$ The global concensus in treatment of mild to moderate acne is usage of fixed combination of topical retinoid and antibiotic. ${ }^{3-5}$ However, topical retinoids also have adverse effects such as irritation, erythema and photosensitivity which can impact the compliance with therapy as well. Hence, the quest for newer safer and effective anti acne drugs has been going on.

Topical 5\% dapsone gel contains sulfone and has an advanced solvent microparticulate delivery system that enables penetration of stratum corneum. ${ }^{6-7}$ Dapsone is known to have antibacterial as well as anti-inflammatory action which may help in reduction of acne. The role of topical retinoids in treating acne is well established. Adapalene is a topical retinoid used in the treatment of acne vulgaris. It acts through the retinoic acid receptors which modulate gene transactivation and gene expression in human keratinocytes inducing anti-comedogenic, anti-inflammatory and immunomodulatory effects. ${ }^{8}$ However, the use of topical retinoids is limited by their cutaneous side effects. But, adapalene is the least irritating retinoid of the 1 lot $^{8}{ }^{8}$ Clindamycin is a topical antibiotic which has been widely used in treatment of acne for many decades. The extensive use of antibiotics in acne has lead 
to the development of resistance to antimicrobial therapy by many pathogens, including Propionibacterium acnes. ${ }^{9}$ Therefore, all the current guidelines strongly advocate limiting the use of monotherapy for prolonged duration in chronic diseases like acne., ${ }^{4,10}$ Combination of topical retinoids and antibiotic can reduce the development of resistance as well as improve therapeutic outcomes. Combination therapy is likely to have more significant effect because it targets almost all the steps in pathogenesis of acne. ${ }^{9}$

\section{Aims of the study}

a. The aim of this study was to compare the efficacy of 5\% Dapsone gel and combination of $1 \%$ clindamycin- $0.1 \%$ adapalene gel in the treatment of mild to moderate acne vulgaris.

b. To study the possible adverse events due to these topical medications

\section{Materials and methods}

This study was conducted in the Dermatology OPD of Belagavi Institute of Medical Sciences Belagavi. Sixty patients who had mild to moderate acne as per Global Acne Grading Scale were enrolled in this study. Written informed consent was obtained from all the patients before being enrolled in the study. Patients who had used any topical/systemic anti acne preparations (including OTC/steroids) in the last 3 weeks, those with severe grade (GAGS >30) acne, patients with known hypersensitivity to any of the study drug, pregnant and lactating women were excluded from the study.

Both gels were repacked in similar looking containers which were coded and randomized so as to blind the investigator and the patient. Patients randomly received the medication such that 30 of them received dapsone gel and other 30 got combination of clindamycinadapalene gel. They were asked to follow up after 4 weeks. Patients were asked to apply a pea sized quantity of drug over the face for $30 \mathrm{~min}$ at night. They were advised sunscreen usage during the daytime (Table 1).

Table I Global Acne Grading Scale (GAGS)

\begin{tabular}{ll}
\hline Location & Factor \\
\hline Forehead & 2 \\
Right cheek & 2 \\
Left Cheek & 2 \\
Nose & $\mathrm{I}$ \\
Chin & $\mathrm{I}$ \\
Chest and Upper back & 3 \\
\hline
\end{tabular}

Each type of lesion is graded depending on the severity as follows: no lesions $=0$, comedones $=1$, papules $=2$, pustules $=3$ and nodules $=4$. Score for each area is calculated $=$ factor multiplied by grade. Global score is sum of local scores. 1-18 is mild, $19-30$ is moderate, $31-38$ is severe and $>39$ is very severe.

\section{Results}

Data was analyzed using Wilcoxon signed rank test (Table 2). In this study total 60 subjects are enrolled age 18-25 years. Males are $48(80 \%)$ and females are $12(20 \%)$. Each group contains 30 subjects (Table 3).
Table 2 Total study subjects

\begin{tabular}{lll}
\hline $\begin{array}{l}\text { Total } \\
\text { subjects }\end{array}$ & $\begin{array}{l}\text { Adapalene- } \\
\text { clindamycin(AC) } \\
\text { group }\end{array}$ & Dapsone group \\
\hline 60 & 30 & 30 \\
\hline
\end{tabular}

Table 3 At 4 weeks

\begin{tabular}{lllll}
$\begin{array}{l}\text { Total } \\
\text { subjects } \\
\text { who } \\
\text { followed } \\
\text { up }\end{array}$ & $\begin{array}{l}\text { AC group } \\
\text { improved }\end{array}$ & $\begin{array}{l}\text { AC group Not } \\
\text { improved }\end{array}$ & $\begin{array}{l}\text { Dapsone } \\
\text { group } \\
\text { improved }\end{array}$ & $\begin{array}{l}\text { Dapsone } \\
\text { group not } \\
\text { improved }\end{array}$ \\
\hline 24 & 7 & 5 & 7 & 5 \\
\hline
\end{tabular}

At the end of 4weeks of study only 24(40\%) subjects followed-up, out of which 12 showed statistically significant improvement in their acne grading (Table 4).

Table 4 Subjects who did not follow up were questioned telephonically

\begin{tabular}{|c|c|c|c|c|c|}
\hline $\begin{array}{l}\text { Subjects } \\
\text { who } \\
\text { did not } \\
\text { follow } \\
\text { up }\end{array}$ & Total & Improved & $\begin{array}{l}\text { Not } \\
\text { improved }\end{array}$ & $\begin{array}{l}\text { Side } \\
\text { effects }\end{array}$ & $\begin{array}{l}\text { Have } \\
\text { not } \\
\text { applied } \\
\text { the } \\
\text { medica- } \\
\text { tion }\end{array}$ \\
\hline AC group & 17 & 6 & 2 & 2 & $\begin{array}{l}7 \\
\text { (Exams- } \\
3, \text { Not } \\
\text { used-4) }\end{array}$ \\
\hline $\begin{array}{l}\text { Dapsone } \\
\text { group }\end{array}$ & 19 & 5 & 8 & I & $\begin{array}{l}5 \\
\text { (Exams-3 } \\
\text { Not } \\
\text { used-2) }\end{array}$ \\
\hline
\end{tabular}

Out of 60, 24 subjects followed-up after 4weeks and reported no adverse events with the medications. 36 subjects who did not followup were questioned telephonically. 3 subjects experienced side effects like dryness and erythema (AC group-2, Dapsone group-1) (Figures $1-4)$.



Figure I Adapalene-clindamycin group before treatment GAGS-2 I. 


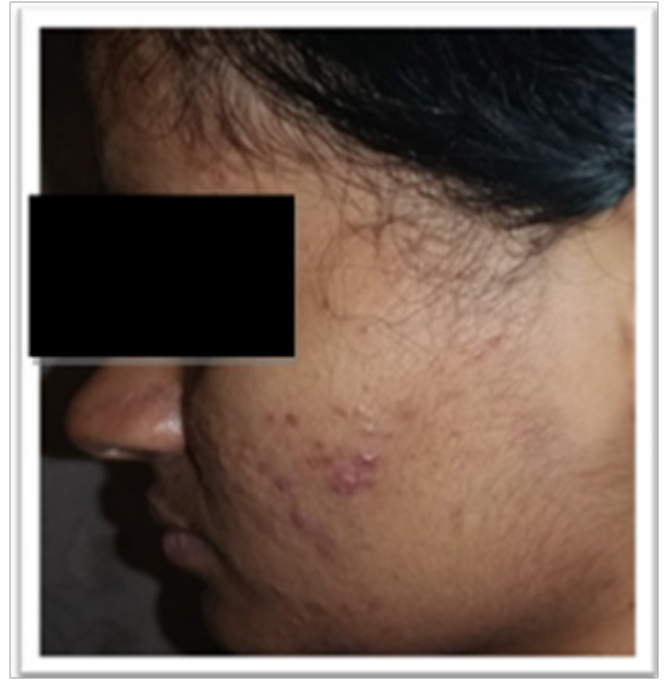

Figure 2 Adapalene-clindamycin groups after 4wks GAGS-I4.

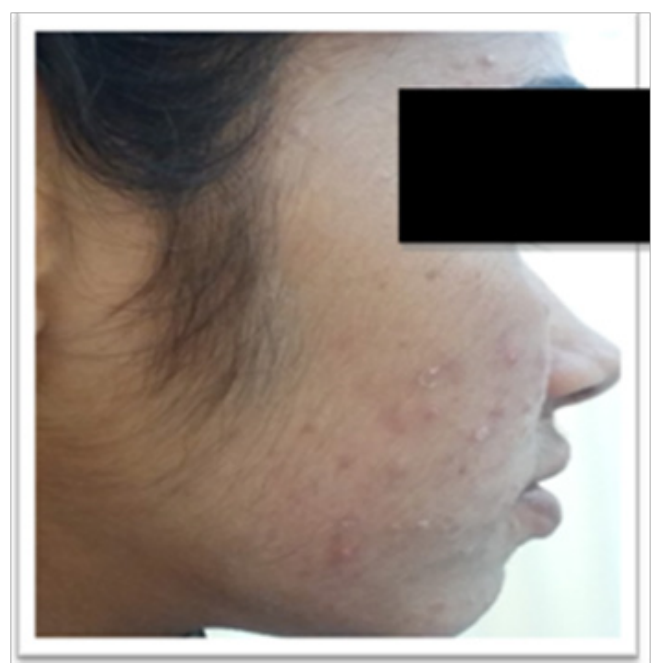

Figure 3 Dapsone gel group before treatment GAGS-I8.

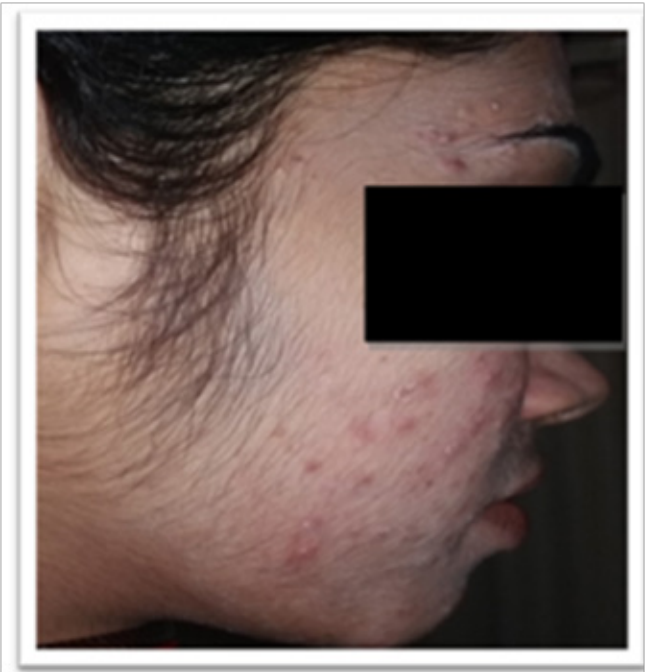

Figure 4 Dapsone gel group after 4wks GAGS-I3.

\section{Discussion}

Acne vulgaris is one of the common skin disorders which dermatologists encounter in their daily practice. The clinical presentation varies from seborrhoea, comedones, erythematous papules, pustules and less frequently nodules, pseudocysts or scarring in few of them. The treatment options are also equally varied ranging from topical therapy (antibiotic creams, retinoids), systemic (antibiotics, retinoids, hormonal therapy), surgical therapy to peels and lasers. ${ }^{11}$ The latest addition to the list is Dapsone gel. There are hardly any studies which have compared the efficacy of Dapsone gel with other topical medications and hence we decided to undertake this study. Dapsone gel is known to act on propionibacterium acne and also on the leucocytes, thereby reducing bacterial colonization as well as inflammation which are two key pathogenic factors in the development of acne.

30patients were assigned to each group and treated for 4 weeks. This showed both drugs had similar efficacy. 36subjects who did not follow-up, were telephonically interviewed, following which our statistics showed that adapalene-clindamycin group had a higher efficacy and less side effects compared to dapsone group.

Most of the studies done earlier with regard to Dapsone gel have evaluated the drug as a standalone therapy. But, we were comparing it to the most commonly recommended anti acne medication. A study done by Pickert et al., ${ }^{12}$ showed 5\% Dapsone gel was clinically effective and well tolerated in mild to moderate acne vulgaris. ${ }^{12} \mathrm{~A}$ study conducted by Lynde $\mathrm{CW}$ et al., ${ }^{13}$ on 101 subjects showed that dapsone $5 \%$ is safe and effective in treatment of mild to moderate inflammatory facial acne. ${ }^{13}$ Another interesting study by Tanghetti et al., ${ }^{14}$ concluded that dapsone gel had favorable outcome in females compared to the male counterparts. ${ }^{14}$ However, we did not see any such gender based bias in our study. Another study by Lucky et al., ${ }^{15}$ concluded that Dapsone gel is safe and effective for long term treatment of acne vulgaris and has a rapid onset of action. ${ }^{15}$

As evident from all these studies, Dapsone gel is an effective and safe anti acne medication. The same was once again established by our study as well. However, in comparison to Adapalene-clindamycin gel it could not match the efficacy in terms of improvement in acne. Adapalene-clindamycin gel showed better results in terms of improvement in the acne and the side effects were slightly more than Dapsone group. But, a good number of patients in the Dapsone group were lost to follow up because their acne did not improve. This highlights the fact that quick response to therapy is a significant factor in deciding the compliance to therapy. If patients see good response, even with bare minimal adverse events they would be more compliant and not otherwise. There are large number of studies to support the fact that adapalene-clindamycin is an effective and safe therapeutic option in the treatment of acne. A study by Percy et al., ${ }^{16}$ showed Adapalene gel is a safe and effective topical agent in the treatment of mild to moderate acne vulgaris in Indian patients. Adapalene may be combined with other topical and oral anti acne drugs. ${ }^{16,17}$ More than $50 \%$ cases in this study did not follow, which reflects the poor compliance to therapy in the Indian scenario.

This was taken up as a pilot study to compare the 2drugs. Even though the number of cases was small, there was a significant dropout. The primary reason for recruiting a limited number of subjects was the cost of medications. This study did not receive any grants and the authors purchased the medications at their own cost. The possible 
reasons for a large number of drop outs were adverse events to the study drug, the subjects were facing academic exams and in few other cases they lacked motivation because of poor response to therapy. Since this study was conducted at a tertiary government hospital, the long waiting queues could also have been a factor for the poor compliance. In order to overcome these pitfalls, we had to analyze some subjects telephonically. This study did not have a scale to analyze the severity of adverse effects. However, it was quite evident that the severity was not much, since only 3 subjects quoted adverse events as a factor for non compliance with the therapy.

\section{Conclusion}

Adapalene-clindamycin gel is more effective compared to Dapsone gel in the treatment of mild to moderate acne vulgaris. The common adverse effects seen were erythema and dryness which was slightly more with Adapalene clindamycin. Limitation of study:

i. The study period was only for 4 weeks and hence, no long term adverse events could be elicited.

ii. $50 \%$ study population did not follow up in person and hence, there could be certain errors.

\section{Acknowledgments}

Approved by Institutional Ethics Committee.

\section{Conflict of interest}

Author declares that there is no conflict of interest.

\section{References}

1. Bergfield WF. Topical retinoids in the management of acne vulgaris. $J$ Drug Dev Clin Pract. 1996;8:151-160.

2. Abell E. Inflammatory diseases of the epidermal appendages and of cartilage. In: Elder D, Elenitsas R, Jaworsky C, et al., editors. Levers Histopathology of the Skin. $8^{\text {th }}$ ed. Philadelphia: Lippincott Raven;1997. p. 403-404.

3. Kubba R, Bajaj AK, Thappa DM, et al. Acne in India: Guidelines for management-IAA consensus document. Indian $J$ Dermatol Venereol Leprol. 2009;75(Suppl 1):1-62.

4. Thiboutot D, Gollnick H, Bettoli V, et al. New insights into the management of acne: An update from the Global Alliance to Improve Outcomes in Acne group. J Am Acad Dermatol. 2009;60(5 Suppl):S1-S50.
5. Thielitz A, Helmdach M, Röpke EM, et al. Lipid analysis of follicular casts from cyanoacrylate strips as a new method for studying therapeutic effects of anti acne agents. Br J Dermatol. 2001;145(1):19-27.

6. Zhu YI, Stiller MJ. Dapsone and sulfones in dermatology: overview and update. J Am Acad Dermatol. 2001;45(3):420-434.

7. Ross CM. The treatment of acne vulgaris with dapsone. Br J Dermatol. 1961;73:367-370.

8. Czemielewski J, Michel S, Bouclier M, et al. Adapalene biochemistry and the evolution of a new topical retinoid for treatment of acne. J Eur Acad Dermatol Venereol. 2001;15(suppl 3):5-12.

9. Dreno B. Bacteriological resistance in acne; a call to action. Eur $J$ Dermatol. 2016;26(2);127-132.

10. Nast A, Dreno B, Bettoli V, et al. European evidence-based (s3) guidelines for the treatment of acne-update 2016 short version. J Eur Acad Dermatol Venereol. 2016;30(8):1261-1268.

11. Rathi SK. Acne vulgaris treatment: The current scenario. Indian $J$ Dermatol. 2011;56(1):7-13.

12. Pickert A, Raimer S. An evalution of dapsone gel 5\% in the treatment of acne vulgaris. Expert opin pharmacother. 2009;10(9);1515-1521.

13. Lynde CW, Andriessen A. Cohort study on the treatment with dapsone 5\% gel of mild to moderate inflammatory acne of the face in women. Skinmed. 2014;12(1):15-21

14. Taghetti E, Harper JC, Oefelein MG. The efficacy and tolerability of dapsone $5 \%$ gel in female Vs males patients with facial and vulgaris, gender as a clinically relevant outcome variable. J Drug Dermatol. 2012;11(12):1417-1421

15. Lucky AW, Maloney JM, Roberts J, et al. Dapsone gel 5\% for the treatment of acne vulgaris, safety and efficacy of long-term (1 year) treatment. $J$ Drug Dermatol. 2007;6(10):981-987.

16. Percy SH. Safety and efficacy of Adapalene gel $0.1 \%$ in acne vulgaris, Result of a post-marketing surveillance study. Indian J Dermatol Venerol Leprol. 2003;69(4):277-280.

17. Wolf JE Jr, Kaplan D, Kraus SJ, et al. Efficacy and tolerability of combined topical treatment of acne vulgaris with adapalene and clindamycin: a multicenter, randomized, investigator-blinded study. $J \mathrm{Am}$ Acad Dermatol. 2003;49(3 Supp1):S211-S217. 